\title{
РЕЖИМ ПИТАНИЯ РАСТЕНИЙ В АГРОЧЕРНОЗЕМАХ В ЗАВИСИМОСТИ ОТ ПРИЕМОВ ОСНОВНОЙ ОБРАБОТКИ
}

\section{PLANT NUTRITION REGIMES IN AGROCHERNOZEMS, DEPENDING ON THE BASIC SOIL TREATMENT}

Власенко Ольга Анатольевна - канд. биол. наук, доц. каф. почвоведения и агрохимии Красноярского государственного аграрного университета, г. Красноярск.

E-mail: ovlasenko07@mail.ru

Применение ресурсосберегающих технологий и минимизация обработок почвы вызывают неоднозначные суждения. Поверхностная обработка почвы, с одной стороны, приводит к накоплению растительных остатков и снижению интенсивности минерализации органического вещества, а с другой - способствует дифрференциации гумусового горизонта по различным показателям плодородия, в том числе и по содержанию элементов питания растений. Цель исследования - оценить влияние минимизации основной обработки на режим элементов питания растений в агрочерноземах Красноярской лесостепи. В условиях полевого опыта изучена динамика нитратного и аммонийного азота, подвижного фоссрора и обменного калия в агрочерноземах при минимизации обработки без применения удобрений. Схема опыта включала три вида основной обработки почвы: вспашка, минимальная обработка дискатором и посев без основной обработки в агроценозах пшеницы и кукурузы. Смешанные образцы почвы отбирали в трехкратной повторности из слоя 0-20 и 20-40 см три раза за вегетацию по всем вариантам опыта, в отобранных образцах определяли содержание элементов питания. Показано, что наибольщей стабильностью в пространстве и во времени отличается содержание подвижного фоосфора и обменного калия. Величина их варьирования (Cv) в слое 0-20 и 20-40 см не превышает 39,9 \% и обусловлена способом основной обработки. Содержание нитратного и аммонийного азота отличается высокой неоднородностью и широ-
Vlasenko Olga Anatolyevna - Cand. Biol. Sci., Assoc. Prof., Chair of Soil Science and Agrochemistry, Krasnoyarsk State Agrarian University, Krasnoyarsk.

E-mail: ovlasenko07@mail.ru

ким варьированием (Cv = 1,8-83 \%). При этом динамика нитратного азота в больщей степени определялась погодными условиями, а не воздельваемой культурой и способом обработки почвы. За годы исследований отмечено, что при минимизации основной обработки агрочернозема содержание подвижных форм фросфора и аммонийного азота увеличивается. $B$ nodnaхотном слое почвы 20-40 см происходит снижение содержания обменного калия, следовательно, поверхностные обработки почвы усиливают дифрференциацию обменного калия по слоям 0-20 и 20-40 см.

Ключевые слова: агрочернозем, минимальная обработка, нитратнылй азот, аммонийньй азот, подвижный фоссфор, обменный калий, пшеница, кукуруза.

The application of resource-saving technologies and minimization of soil treatments cause ambiguous judgments. Surface soil treatment on the one hand leads to the accumulation of plant residues and the decrease in the intensity of mineralization of organic matter, and on the other hand contributes to the differentiation of the humus horizon, by various indicators fertility, including the content of plant nutrition. The purpose of the study is to assess the impact of minimization of basic soil treatments on the plants nutrition regime in the agrochernozems of the Krasnoyarsk forest steppe. In the conditions of field experiment the dynamics of nitrate and ammonium nitrogen, mobile phosphorus and potassium exchange in agrochernozems has been studied while minimizing treatment without the use of fertilizers. 
The experiment scheme includes three types of basic soil treatment: plowing, minimal disk treatment and sowing without basic soil processing in wheat and maize agrocenosis. Mixed soil samples have been selected in three times the replication of the layer 0-20 and 20-40 cm three times for vegetation on all variants of the experiment, in the selected samples the content of plant nutrition elements is determined. It is shown that the greatest stability in space and time has the content of mobile phosphorus and potassium exchange. The magnitude of their variation (Cv) in the layer $0-20$ and $20-40 \mathrm{~cm}$ does not exceed $39.9 \%$ and is due to the method of basic processing. Nitrate and ammonium nitrogen content is highly heterogeneous and varied (Cv 1.8 to $83 \%$ ). At the same time, the dynamics of nitrate nitrogen is more determined by the weather conditions than by the culture and way of processing the soil. Over the years of the research, it has been noted that when the main processing of agrochernozems is minimized, the content of mobile forms of phosphorus and ammonium nitrogen increases. In the plowscented layer of soil $20-40 \mathrm{~cm}$ there is a decrease in the content of potassium exchange, therefore, surface soil processing increases the differentiation of potassium exchange by layers 0-20 and 20-40 cm.

Keywords: agrochernozem, nitrate nitrogen, ammonium nitrogen, movable phosphorus, exchange potassium, minimal processing, wheat, corn.

Введение. Обработка почвы рассматривается в качестве фактора почвообразования наряду с естественными условиями [1]. Агрогенное воздействие изменяет водно-воздушный и окислительно-востановительный режим в почвах, их ферментативную активность и фризические свойства [2], способствует ускорению процессов минерализации гумуса [3], снижению содержания агрономически ценных фрракций [4]. Использование ресурсосберегающих технологий и сокращение обработок почвы вызывают разные, иногда противоположные мнения [5]. Замена вспашки почвозащитными технологиями, с одной стороны, приводит к накоплению мортмассы на поверхности и внутри почвы, способствует снижению интенсивности минерализации органического вещества, а с другой стороны - усиливает диффференциацию гумусового горизонта по различным показателям плодородия, в том числе и по содержанию элементов питания растений.
Цель исследования. Оценить влияние минимизации основной обработки на режим элементов питания растений в агрочерноземах Красноярской лесостепи.

Задачи исследования: определение динамики содержания элементов питания растений при возделывании пшеницы и кукурузы в вариантах с традиционной вспашкой, минимальной обработкой и в варианте без проведения основной обработки почвы.

Материалы, условия и методы. Исследования проведены в 2016-2017 гг. на территории учебного хозяйства «Миндерлинское», которое находится в центральной части Красноярской лесостепи на юго-западе Средней Сибири $\left(56^{\circ} 25^{\prime} \mathrm{N}\right.$ и $\left.92^{\circ} 53^{\prime} \mathrm{E}\right)$. Объект исследования - комплекс агрочерноземов глинисто-иллювиальных (типичных, оподзоленных, гидрометаморфизированных) и агрочерноземов криогенномицелярных тяжелосуглинистых. Перед закладкой опыта почва характеризовалась высоким и очень высоким содержанием гумуса (6,1$11,1 \%)$, очень высокой суммой обменных оснований $(53,2-62,0$ ммоль·100·г-1), нейтральной, слабокислой и слабощелочной реакцией почвенного раствора ( $\left.\mathrm{pH}_{2} \mathrm{O} 6,5-7,9\right)$, низким и средним содержанием минеральных форм азота (9,4-23 мг/кг), низким и повышенным содержанием обменного фоссрора (30-125 мг/кг), высоким и очень высоким содержанием обменного калия (165-385 мг/кг). Оценку влияния минимизации основной обработки на режим питания растений в агрочерноземах проводили в агроценозе яровой пшеницы (Triticum aestivum L.) сорта Новосибирская 15, кукурузы (Zea mais L.) сорта Катерина СВ по следующей схеме:

1) отвальная обработка ПН-5-35 на глубину 23-25 cM;

2) минимальная обработка дискатором БДШ-5,6 на глубину 12-14 см;

3) нулевая обработка (посев без основной обработки сеялкой Агратор 4,8).

В 2016 году все культуры возделывали по зерновым предшественникам. В 2017 году предшественником пшеницы был занятый пар, предшественником кукурузы - пшеница. Все опыты проводились на неудобренном фоне с применением средств защиты растений [6]. Опыт проведен в соответствии с методическими требованиями к полевым исследованиям [7]. Общая площадь опытных делянок 1500 м², 


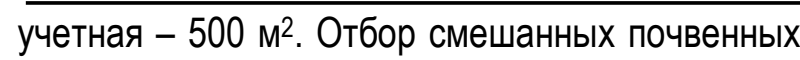
образцов проводили в июне, июле и августе. Повторность отбора 3-кратная. Глубина отбора 0-20 и 20-40 см. В почвенных образцах определяли: содержание нитратного и аммонийного азота, подвижного фосфрора и калия по Чирикову согласно общепринятым методикам [8]. Результаты исследований обработаны методами вариационной статистики и дисперсионного анализа, при котором оценивался показатель силы влияния (ПСВ, \%) разных фракторов (возделываемая культура, период вегетации, спо- соб обработки и глубина почвы) на динамику элементов питания.

Погодные условия вегетации в годы проведения опытов были достаточно экстремальными (табл. 1). Анализ метеоданных [9] показал, что сумма активных температур составила 1838$1970{ }^{\circ} \mathrm{C}$ при среднемноголетней величине для данной местности $1800^{\circ} \mathrm{C}$. В среднем гидротермический коэфффициент в условиях хозяйства за весь период наблюдений был 1,0-1,1 при среднемноголетней норме 1,3-1,4, при этом его амплитуда колебалась в пределах от 0,3 до 2,7.

Гидротермические условия вегетационного периода 2016-2017 гг.

Таблица 1 (по данным метеостанции «Сухобузимская», Красноярского края)

\begin{tabular}{|c|c|c|c|}
\hline Месяц & $\begin{array}{c}\text { Температура } \\
\text { воздуха, }{ }^{\circ} \mathrm{C}\end{array}$ & Осадки, мм & ГТК \\
\hline \multicolumn{4}{|c|}{2016 год } \\
\hline Май & 8,1 & 44,0 & 2,7 \\
\hline Июнь & 18,4 & 21,6 & 0,4 \\
\hline Июль & 20,4 & 57,0 & 0,9 \\
\hline Август & 17,0 & 54,0 & 1,0 \\
\hline \multicolumn{4}{|c|}{ Сумма активных температур $=1838,4^{\circ} \mathrm{C}$} \\
\hline \multicolumn{4}{|c|}{2017 год } \\
\hline Май & 10,8 & 27,7 & 1,0 \\
\hline Июнь & 22,1 & 20,2 & 0,3 \\
\hline Июль & 19,5 & 78,5 & 1,3 \\
\hline Август & 16,8 & 81,0 & 1,6 \\
\hline \multicolumn{4}{|c|}{ Сумма активных температур $=1969,5^{\circ} \mathrm{C}$} \\
\hline \multicolumn{4}{|c|}{ Среднемноголетние показатели } \\
\hline Май & 10,0 & 32,0 & 1,38 \\
\hline Июнь & 16,4 & 44,0 & 1,27 \\
\hline Июль & 18,9 & 69,0 & 1,28 \\
\hline Август & 14,2 & 62,0 & 1,34 \\
\hline \multicolumn{4}{|c|}{ Сумма активных температур $=1800^{\circ} \mathrm{C}$} \\
\hline
\end{tabular}

Таким образом, вегетационные периоды наблюдений 2016-2017 гг. были более теплые и сухие по сравнению со среднемноголетними показателями и отличались сочетанием экстремально засушливых и экстремально влажных периодов.

Результаты исследования и их обсуждение. В почвах Сибири содержание нитратных форм азота характеризуется низким уровнем, что связано с длительным сезонным промерзанием почвенного профиля и коротким вегетационным периодом, в таких условиях нитратные формы азота не успевают накапливаться. Часть из них тут же усваивается растениями, а другая часть вымывается обильными осадками второй половины лета [10]. Известно [11-13], что динамика минеральных форм азота в агропочвах в большей степени определяется не только метеорологическими условиями вегетационного периода, но и агротехническими мероприятиями, главным из которых является внесение удобрений. В данном опыте без применения удобрений обеспеченность нитратными формами азота менялась от средней до очень низкой (табл. 2). При возде- 
лывании пшеницы и кукурузы происходило существенное снижение содержания нитратного азота в середине и в конце вегетации, что связано с его выносом культурами в пик прироста фитомассы в июле и дальнейшим вымыванием из почвы в августе 2017 г. в связи с избыточным увлажнением. Коэффицциент вариации данных в течение вегетации по содержанию нитратного азота в слое почвы 0-20 и 20-40 см при разной обработке почвы изменялся от незначительного 1,8 до очень высокого 83,3 \%, при этом с глубиной степень варьирования возрастала (табл. 3).
На динамику нитратного азота в агрочерноземе существенное влияние (р-значение < 0,05 ) оказали изменения погодных условий в течение вегетации. Показатель силы влияния фрактора «период вегетации» составил 59,9 \% (табл. 4). При этом возделываемая культура, способ обработки почвы и глубина существенного влияния не оказывали. В целом за вегетационные периоды 2016-2017 гг. обеспеченность нитратным азотом в агрочерноземах в слое 0-20 см была очень низкой, в слое 20-40 см - низкой [14].

Таблица 2

\section{Динамика элементов питания в агрочерноземах (по усредненным данным 2016-2017 гг.), мг/кг}

\begin{tabular}{|c|c|c|c|c|c|c|c|c|c|c|}
\hline \multirow{3}{*}{ Культура } & \multirow{3}{*}{ Глубина, см } & \multicolumn{9}{|c|}{ Способ обработки и срок определения } \\
\hline & & \multicolumn{3}{|c|}{ Отвальная } & \multicolumn{3}{|c|}{ Минимальная } & \multicolumn{3}{|c|}{ Нулевая } \\
\hline & & июнь & июль & август & июнь & июль & август & июнь & июль & август \\
\hline \multicolumn{11}{|c|}{ Нитратный азот } \\
\hline \multirow{2}{*}{ Кукуруза } & $0-20$ & 16,3 & 8,8 & 3,5 & 15,0 & 12,0 & 4,5 & 16,8 & 6,2 & 3,0 \\
\hline & $20-40$ & 9,4 & 7,5 & 2,0 & 6,3 & 6,3 & 6,5 & 11,0 & 5,1 & 4,2 \\
\hline \multirow{2}{*}{ Пшеница } & $0-20$ & 15,0 & 12,0 & 5,0 & 15,5 & 6,7 & 3,8 & 13,8 & 3,8 & 3,8 \\
\hline & $20-40$ & 11,0 & 9,4 & 3,8 & 15,0 & 5,0 & 5,0 & 6,3 & 3,8 & 8,8 \\
\hline \multicolumn{11}{|c|}{ Аммонийный азот } \\
\hline \multirow{2}{*}{ Кукуруза } & $0-20$ & 13,0 & 9,5 & 15,2 & 20,0 & 17,5 & 15,7 & 21,5 & 12,5 & 10,3 \\
\hline & $20-40$ & 17,0 & 13,8 & 13,5 & 23,0 & 38,5 & 12,4 & 17,0 & 35,0 & 15,4 \\
\hline \multirow{2}{*}{ Пшеница } & $0-20$ & 17,0 & 12,5 & 17,5 & 21,5 & 15,0 & 15,0 & 20,0 & 20,0 & 14,0 \\
\hline & $20-40$ & 13,0 & 10,0 & 17,0 & 22,5 & 25,0 & 18,5 & 20,0 & 33,8 & 12,5 \\
\hline \multicolumn{11}{|c|}{ Подвижный фоссфор } \\
\hline \multirow{2}{*}{ Кукуруза } & $0-20$ & 60,0 & 112,5 & 75,0 & 112,5 & 62,5 & 112,0 & 65,0 & 90,0 & 120,0 \\
\hline & $20-40$ & 30,0 & 112,5 & 65,0 & 62,5 & 92,5 & 55,0 & 80,0 & 90,0 & 95,0 \\
\hline \multirow{2}{*}{ Пшеница } & $0-20$ & 65,0 & 72,5 & 70,0 & 65,0 & 90,0 & 70,0 & 100,0 & 125,0 & 110,0 \\
\hline & $20-40$ & 62,5 & 80,0 & 50,0 & 62,5 & 85,0 & 45,0 & 70,0 & 90,0 & 95,0 \\
\hline \multicolumn{11}{|c|}{ Обменный калий } \\
\hline \multirow{2}{*}{ Кукуруза } & $0-20$ & 253,9 & 299,2 & 304,8 & 173,5 & 203,3 & 188,4 & 177,8 & 232,1 & 166,6 \\
\hline & $20-40$ & 258,7 & 299,3 & 252,2 & 153,6 & 182,2 & 167,9 & 159,2 & 155,6 & 134,7 \\
\hline \multirow{2}{*}{ Пшеница } & $0-20$ & 275,2 & 385,0 & 194,9 & 264,7 & 199,6 & 232,2 & 319,6 & 283,4 & 172,9 \\
\hline & $20-40$ & 222,5 & 282,0 & 182,7 & 259,0 & 210,9 & 162,7 & 181,7 & 150,4 & 147,7 \\
\hline
\end{tabular}

В это же время исследования $[15,16]$ по влиянию способов обработки и предшественников на содержание нитратов на неудобренном фоне в почвах лесостепной зоны Красноярского края показали низкую и очень низкую обеспеченность азотом и достоверное влияние на активизацию процессов нитратонакопления от- вальной вспашки по сравнению с поверхностными обработками. Таким образом, экстремально засушливые условия середины вегетации 2016 и 2017 гг. неблагоприятно отразились на биологической активности почвы и, возможно, снизили ее нитрификационную способность. 
Статистические параметры содержания элементов питания в агрочерноземах, мг/кг

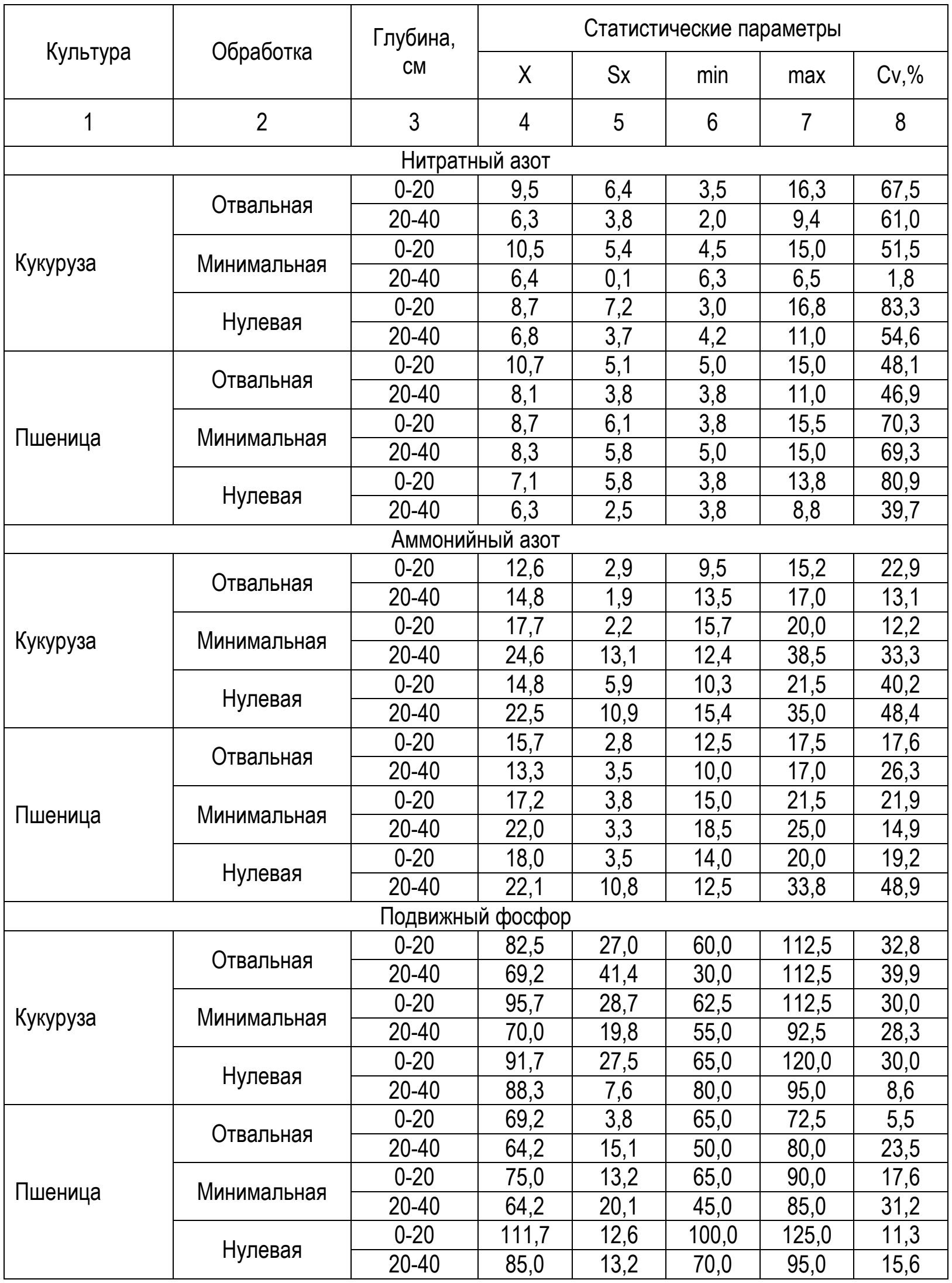


Вестник КрасТАУ. 2020. № 6

\begin{tabular}{|c|c|c|c|c|c|c|c|}
\hline \multicolumn{8}{|c|}{ Окончание табл. 3} \\
\hline 1 & 2 & 3 & 4 & 5 & 6 & 7 & 8 \\
\hline \multicolumn{8}{|c|}{ Обменный калий } \\
\hline \multirow{6}{*}{ Кукуруза } & \multirow{2}{*}{ Отвальная } & $0-20$ & 286,0 & 27,9 & 253,9 & 304,8 & 9,8 \\
\hline & & $20-40$ & 270,1 & 25,5 & 252,2 & 299,3 & 9,5 \\
\hline & \multirow{2}{*}{ Минимальная } & $0-20$ & 188,4 & 14,9 & 173,5 & 203,3 & 7,9 \\
\hline & & $20-40$ & 167,9 & 14,3 & 153,6 & 182,2 & 8,5 \\
\hline & \multirow{2}{*}{ Нулевая } & $0-20$ & 192,2 & 35,0 & 166,6 & 232,1 & 18,2 \\
\hline & & $20-40$ & 149,8 & 13,2 & 134,7 & 159,2 & 8,8 \\
\hline \multirow{6}{*}{ Пшеница } & \multirow{2}{*}{ Отвальная } & $0-20$ & 285,0 & 95,4 & 194,9 & 385,0 & 33,5 \\
\hline & & $20-40$ & 229,1 & 50,0 & 182,7 & 282,0 & 21,8 \\
\hline & \multirow{2}{*}{ Минимальная } & $0-20$ & 232,2 & 32,6 & 199,6 & 264,7 & 14,0 \\
\hline & & $20-40$ & 210,9 & 48,2 & 162,7 & 259,0 & 22,8 \\
\hline & \multirow{2}{*}{ Нулевая } & $0-20$ & 258,6 & 76,4 & 172,9 & 319,6 & 29,5 \\
\hline & & $20-40$ & 159,9 & 18,9 & 147,7 & 181,7 & 11,8 \\
\hline
\end{tabular}

Известно [17], что нитратная и аммонийная формы азота фризиологически равноценны для растений, однако их использование культурами в полевых условиях зависит от многих факторов: уровня кислотности, гранулометрического состава, гидротермического режима, предшественников, способов обработки почвы [18]. В изученных агрочерноземах содержание аммонийного азота в течение вегетации колебалось от очень низкого до высокого. В вариантах с посевом без основной обработки существенно возрастал коэффициент вариации данных по содержанию аммонийного азота в течение вегетации до 40,2-48,9 \%. При минимальной обработке и отвальной вспашке размах сезонного варьирования содержания аммонийного азота снижался до 12,2-33,3 \%.

\section{Показатель силы влияния различных факторов (ПСВ) на содержание элементов питания в агрочерноземах, \%}

\begin{tabular}{|l|c|c|c|c|}
\hline \multicolumn{1}{|c|}{ Фактор } & $\begin{array}{c}\text { Нитратный } \\
\text { азот }\end{array}$ & Аммонийный азот & $\begin{array}{c}\text { Подвижный } \\
\text { фоссрор }\end{array}$ & Обменный калий \\
\hline Обработка & 2,1 & $17,6^{*}$ & $19,1^{*}$ & $33,7^{*}$ \\
\hline Глубина слоя почвы & 6,6 & 8,8 & 9,8 & $12,8^{*}$ \\
\hline Период вегетации & $59,9^{*}$ & 12,5 & 16,3 & 11,4 \\
\hline Культура & 0,04 & 0,1 & 1,2 & 2,9 \\
\hline
\end{tabular}

* - влияние достоверно (р-значение <0,05).

Пространственное варьирование аммонийного азота в каждый из сроков отбора при отвальной и минимальной обработке было средним (24-28 \%), а при посеве без основной обработки пространственная неоднородность повысилась до 36-42 \%. При минимальной обработке и посеве без основной обработки в слое почвы 20-40 см обнаружено существенное увеличение содержания аммонийных фрорм азота до высокого класса обеспеченности (ПСВ фрактора «обработка» - 17,6 \%) в середине вегетации. Следова- тельно, минимизация обработки, накопление в почве растительных остатков кукурузы и пшеницы, снижение аэрации верхнего слоя почвы способствуют усилению процессов аммонификации.

Несмотря на высокое содержание гумуса и тяжелый гранулометрический состав, обеспеченность 0-40 см слоя почв подвижным фоссфором была низкой (50-125 мг/кг) при незначительной и средней изменчивости его в пространстве и во времени ( $\mathrm{Cv}=5,5-39,9 \%$ \%). Исходно низкое содержание подвижного фосфрора 
в почвах связано с длительным отсутствием применения фоссфорсодержащих удобрений на данном участке. На динамику изменения содержания подвижного фоосфора в почве возделываемые культуры и период вегетации существенного влияния не оказывали. Результаты показали достоверное влияние основной обработки на изменчивость подвижного фосффора в почве $(П С В=19,1 \%)$. Так, в слое почвы 0-20 см в вариантах с минимальной и нулевой обработкой за два года произошло увеличение содержания подвижного фосфрора в 1,1-1,3 раза по сравнению с отвальной вспашкой. При минимизации обработок фосфор поступает в почву вместе с растительными остатками, однако он прочно связан с органическим веществом и переход его в минеральные фрормы происходит по мере разложения мортмассы. Подобные результаты были получены при изучении антропогенного воздействия на фоссратный режим черноземной почвы в Пензенской области [18], где показано, что без применения удобрений содержание подвижного фоссрора в черноземах не превышало $40 \mathrm{mг/кг,} \mathrm{применение} \mathrm{в} \mathrm{течение} \mathrm{трех} \mathrm{лет}$ органических удобрений в виде десреката, навоза и соломы привело к увеличению подвижного фоссрора в 1,3-1,7 раза. В опытах, проведенных на территории Канской лесостепи Красноярского края [19], также показано увеличение содержания подвижного фоссфора при минимизации основной обработки почвы.

Содержание обменного калия в агрочерноземах Красноярской лесостепи характеризуется высокой и очень высокой обеспеченностью для данных культур (134-385 мг/кг), характер его пространственной изменчивости варьировал от низкого до среднего уровня ( $\mathrm{Cv}=7,9-33,5 \%)$. В условиях умеренно сухого и континентального климата с неравномерным выпадением осадков и чередованием периодов сильного иссушения почвы и ее обильного смачивания, по мнению [20], содержание обменного калия в почвах увеличивается вместе с уменьшением влажности и нарастанием температуры в июньский и июльский периоды. Однако наши исследования показали отсутствие достоверного увеличения содержания обменного калия в агрочерноземах в середине вегетации. В данном случае на динамику изменений содержания обменного калия в агрочерноземе существенное влияние оказала обработка (ПСВ=33,7 \%). Кроме этого обнаружена дифференциация обменного калия по слоям (ПСВ = 12,8 \%), В слое почвы 0-20 см содержание обменного калия было в 1,1-1,2 раза выше по сравнению со слоем почвы 20-40 см. Снижение содержания обменного калия в подпахотном горизонте произошло как в агроценозе пшеницы, так и в агроценозе кукурузы при минимальной и нулевой обработке по сравнению с отвальной вспашкой. Таким образом, минимизация обработки способствует радиальной дифференциации обменного калия.

\section{Выводы}

1. Динамика нитратного азота в агрочерноземах в течение вегетационных периодов характеризовалась высокой степенью вариабельности и была обусловлена изменением погодных условий.

2. Содержание аммонийного азота также имело высокую вариабельность, которая определялась способом основной обработки. При минимизации обработки произошло существенное увеличение содержания аммонийного азота с низкого до среднего класса обеспеченности.

3. Содержание подвижного фоссфора и обменного калия имело среднюю вариабельность в течение вегетации, которая не определялась гидротермическими условиями. Минимизация обработки способствовала увеличению содержания подвижного фоосфора в 1,1-1,3 раза и снижению содержания обменного калия в 1,11,2 раза.

4. В условиях минимизации обработки пространственное распределение элементов питания в слое 0-20 и 20-40 см в агрочерноземах обладает существенной изменчивостью. Наибольшей стабильностью в пространстве и во времени отличается содержание подвижного фосфора и обменного калия. Содержание нитратного и аммонийного азота отличается большей неоднородностью и более широким пределом варьирования во времени.

\section{Литература}

1. Иванов А.Л., Лебедева И.И., Гребенников А.М. Факторы и условия антропогенной трансформации черноземов, методология 
изучения эволюции почвообразования // Бюллетень Почвенного института им. В.В. Докучаева. 2013. Вып. 72. С. 26-46.

2. Анохина Н.С. Влияние приемов основной обработки почвы и удобрений на гумусное состояние и фрерментативную активность чернозема выщелоченного южной лесостепи Республики Башкортостани: дис. ... канд. с.-Х. наук. Уфра, 2011.

3. Семенов В.М., Когут Б.М. Почвенное органическое вещество. М. : ГЕОС, 2015. 233 с.

4. Кураченко Н.Л., Картавых А.А. Агрофизическое состояние черноземов Красноярской лесостепи в условиях ресурсосберегающих технологий основной обработки // Земледелие. 2017. № 2. С. 17-19.

5. Кирюшин В.И. Проблема минимизации обработки почвы: перспективы развития и задачи исследований // Земледелие. 2013. № 7. C. 3-6.

6. Ивченко В.К., Михайлова З.И. Влияние различных обработок почвы и средств интенсификации на продуктивность зерновых культур // Вестник КрасГАУ. 2017. № 4. C. 3-10.

7. Доспехов Б.А. Методика полевого опыта. М.: Колос, 1985.416 c.

8. Агрохимические методы исследования почв / под ред. А.В. Соколова. М.: Наука, 1975. $487 \mathrm{c}$.

9. Офрициальный сайт: rp5.ru / 000 «Расписание погоды» [СПб.], 2004-2020. URL: http://rp5.ru/Погода_в_Сухобузимском (дата обращения: 25.08.2019).

10. Рудой Н.Г. Агрохимия почв Средней Сибири: учеб. пособие. Красноярск: Изд-во КрасГАУ, 2004. 167 c.

11. Гамзиков Г.П. Агрохимия азота в агроценозах. Новосибирск: Новосиб. гос. аграр. ун-т, 2013. $790 \mathrm{c}$

12. Назарюк В.М. Баланс и транссрормация азота в агроэкосистемах. Новосибирск: Изд-во СО РАН, 2002. $253 \mathrm{c}$.

13. Уваров Г.И. Карабутов А.П. Азотный режим чернозема в зависимости от удобрений и приемов обработки // Научные ведомости. Серия Естественные науки. 2013. № 24 (167). Вып. 25. С. 105-110.

14. Практические рекомендации азотного питания полевых культур и по применению азотных удобрений в сибирском земледелии. М.: Росинформагротех, 2018. 48 c.

15. Сорокина О.A., Кайль А.В. Оценка обеспеченности почв нитратным азотом по предшественникам в лесостепной зоне // Аграрная наука - сельскому хозяйству: мат-лы XI междунар. науч.-практ. конф. Барнаул, 2016. C. 242-243.

16. Кайль А.В. Влияние традиционной и минимальной систем обработки почвы на содержание в почве нитратного азота // Вестник КрасГАУ. 2019. № 2. С. 191-198.

17. Прянишников Д.Н. Аммиак, нитраты и нитриты как источник азота для высших растений: из результатов вегетационных опытов. 1926. T. 13. С. 1-235.

18. Курносова Е.В., Гришин Г.Е. Антропогенное воздействие на фосфатный режим черноземной почвы // Вестник Ульяновской государственной сельскохозяйственной академии. 2013. № 3 (23). С. 19-24.

19. Кураченко Н.Л. Пространственновременная динамика агрохимических показателей чернозема в условиях минимальной обработки // Проблемы современной аграрной науки: мат-лы междунар. науч. конф. Красноярск, 2018. С. 42-45.

20. Бугаков П.С., Горбачева С.М., Чупрова В.В. Почвы Красноярского края. Красноярск, 1981. 127 C.

\section{Literatura}

1. Ivanov A.L., Lebedeva I.I., Grebennikov A.M. Faktory i uslovija antropogennoj transformacii chernozemov, metodologija izuchenija jevoljucii pochvoobrazovanija // Bjulleten' Pochvennogo instituta im. V.V. Dokuchaeva. 2013. Vyp. 72. S. 26-46.

2. Anohina N.S. Vlijanie priemov osnovnoj obrabotki pochvy i udobrenij na gumusnoe sostojanie i fermentativnuju aktivnost' chernozema vyshhelochennogo juzhnoj lesostepi Respubliki Bashkortostani: dis. ... kand. s.-h. nauk. Ufa, 2011.

3. Semenov V.M., Kogut B.M. Pochvennoe organicheskoe veshhestvo. M. : GEOS, 2015. $233 \mathrm{~s}$.

4. Kurachenko N.L., Kartavyh A.A. Agrofizicheskoe sostojanie chernozemov 
Krasnojarskoj lesostepi v uslovijah resursosberegajushhih tehnologij osnovnoj obrabotki // Zemledelie. 2017. № 2. S. 17-19.

5. Kirjushin V.I. Problema minimizacii obrabotki pochvy: perspektivy razvitija i zadachi issledovanij // Zemledelie. 2013. № 7. S. 3-6.

6. Ivchenko V.K., Mihajlova Z.I. Vlijanie razlichnyh obrabotok pochvy i sredstv intensifikacii na produktivnost' zernovyh kul'tur // Vestnik KrasGAU. 2017. № 4. S. 3-10.

7. Dospehov B.A. Metodika polevogo opyta. M.: Kolos, 1985. $416 \mathrm{~s}$.

8. Agrohimicheskie metody issledovanija pochv / pod red. A.V. Sokolova. M.: Nauka, 1975. 487 s.

9. Oficial'nyj sajt: rp5.ru / 000 «Raspisanie pogody» [SPb.], 2004-2020. URL: http://rp5.ru/Pogoda_v_Suhobuzimskom (data obrashhenija: 25.08.2019).

10. Rudoj N.G. Agrohimija pochv Srednej Sibiri: ucheb. posobie. Krasnojarsk: Izd-vo KrasGAU, 2004. $167 \mathrm{~s}$.

11. Gamzikov G.P. Agrohimija azota v agrocenozah. Novosibirsk: Novosib. gos. agrar. un-t, $2013.790 \mathrm{~s}$.

12. Nazarjuk V.M. Balans i transformacija azota $v$ agrojekosistemah. Novosibirsk: Izd-vo SO RAN, 2002. $253 \mathrm{~s}$.

13. Uvarov G.I. Karabutov A.P. Azotnyj rezhim chernozema $v$ zavisimosti ot udobrenij $\mathrm{i}$ priemov obrabotki // Nauchnye vedomosti. Serija Estestvennye nauki. 2013. № 24 (167). Vyp. 25. S. 105-110.
14. Prakticheskie rekomendacii azotnogo pitanija polevyh kul'tur i po primeneniju azotnyh udobrenij $\mathrm{V}$ sibirskom zemledelii. M.: Rosinformagroteh, 2018. $48 \mathrm{~s}$.

15. Sorokina O.A., Kajl' A.V. Ocenka obespechennosti pochv nitratnym azotom po predshestvennikam v lesostepnoj zone /I Agrarnaja nauka - sel'skomu hozjajstvu: matly XI mezhdunar. nauch.-prakt. konf. Barnaul, 2016. S. 242-243.

16. Kajl' A.V. Vlijanie tradicionnoj i minimal'noj sistem obrabotki pochvy na soderzhanie $v$ pochve nitratnogo azota // Vestnik KrasGAU. 2019. № 2. S. 191-198.

17. Prjanishnikov D.N. Ammiak, nitraty i nitrity kak istochnik azota dlja vysshih rastenij: iz rezul'tatov vegetacionnyh opytov. 1926. T. 13. S. 1-235.

18. Kurnosova E.V., Grishin G.E. Antropogennoe vozdejstvie na fosfatnyj rezhim chernozemnoj pochvy II Vestnik Ul'janovskoj gosudarstvennoj sel'skohozjajstvennoj akademii. 2013. № 3 (23). S. 19-24.

19. Kurachenko N.L. Prostranstvenno-vremennaja dinamika agrohimicheskih pokazatelej chernozema $v$ uslovijah minimal'noj obrabotki // Problemy sovremennoj agrarnoj nauki: matly mezhdunar. nauch. konf. Krasnojarsk, 2018. S. 42-45.

20. Bugakov P.S., Gorbacheva S.M., Chuprova V.V. Pochvy Krasnojarskogo kraja. Krasnojarsk, 1981.127 s. 